\title{
LIQUID CRYSTALLINE POLYURETHANES STUDIED BY POSITRON ANNIHILATION METHOD
}

\author{
A. Baranowski ${ }^{a}$, M. DęBowska ${ }^{a *}$, A. JANKoWski ${ }^{b}$, K. JeriE ${ }^{a}$, \\ P. PENCZEK ${ }^{c}$, J. RudzińsKa-Girulska ${ }^{a}$, B. SzCZEPaniaK ${ }^{c}$ \\ AND A. WolińsKa-GraBCZYK ${ }^{b \dagger}$ \\ a Institute of Experimental Physics, University of Wrocław \\ Maxa Borna 9, 50-204 Wrocław, Poland \\ ${ }^{b}$ Institute of Coal Chemistry PAN, Sowińskiego 5, 44-101 Gliwice, Poland \\ c Industrial Chemistry Research Institute, Rydygiera 8, 01-793 Warszawa, Poland
}

A series of liquid crystalline polyurethanes of different both flexible spacer length and mesogenic group content was studied by means of positron annihilation method. The investigated polymers were targeted on the separation of aromatic hydrocarbons from their mixtures with aliphatic ones. The effect of modification of the liquid crystalline polyurethane chain on the polyurethane free volume size and free volume distribution was determined on the basis of the positron annihilation lifetime spectra. In the positron annihilation lifetime spectra measured for the samples under study two long components of several nanoseconds, characteristic of o-Ps decaying by pick-off, occurred. The correlation of the values of the $o$-Ps lifetime with the size of the free volume region allowed to recover the free volume distributions with the use of the method employing the numerical Laplace inversion technique. The obtained results were compared with the diffusion data on the mobility of liquid hydrocarbons in the liquid crystalline polyurethanes enabling the correlations between polymer structure and its transport properties to be evaluated.

PACS numbers: $71.60 .+z, 78.70 . B j, 81.20 . S h, 82.30 . H k$

\section{Introduction}

Liquid mixtures can be separated very effectively by pervaporation using dense polymer membrane. Since the separation effect is caused by different solubilities and diffusivities of the components in the membrane polymer, the chemical

*To whom correspondence on positron annihilation should be addressed.

†To whom correspondence on chemistry of the samples should be addressed. 
architecture of the polymer and its morphology are the most effective parameters in differentiating the transport rates and the separation efficiencies.

Therefore, it is of great interest to study free volume size and distribution of structurally different LC (liquid crystalline) polyurethanes with respect to their transport properties. The correlations which are to be found should help to reveal transport mechanism in such systems and should facilitate the designing of the new polymer materials with tailor-made transport properties.

\section{Experimental}

\subsection{Preparation of samples}

Liquid crystalline polyurethanes were synthesized by the prepolymer two-step technique using poly(oxytetramethylene)diol (PTMO), 2,4-tolylene diisocyanate (TDI), 4,4'-bis(2-hydroxyethoxy)biphenyl (BHBP) and $N, N$-dimethylformamide (DMF) as a solvent. Preparation and physicochemical properties of these polymers have been published in [1-4].

PTMO diols with different molecular weights $\left(\bar{M}_{n}=2000,1000,650\right)$ and different initial composition of BHBP and PTMO diols (3:1, 1:1) were applied resulting in LC polyurethanes with different structure and properties (Table I).

TABLE I

Characteristics of LC polyurethanes.

\begin{tabular}{|c|c|c|c|c|c|c|}
\hline $\begin{array}{l}\text { Sample } \\
\text { code }\end{array}$ & Composition & $\begin{array}{l}\text { Molecular } \\
\text { weight } \\
\bar{M}_{n}\end{array}$ & $\bar{M}_{w} / \bar{M}_{n}$ & $\begin{array}{c}\text { Soft } \\
\text { segments } \\
\text { weight } \\
\text { fract. [\%] }\end{array}$ & $\begin{array}{c}\text { Glass } \\
\text { transition } \\
\text { temp. } \\
{\left[{ }^{\circ} \mathrm{C}\right]^{* *}}\end{array}$ & $\begin{array}{c}\text { Phase } \\
\text { separation } \\
\text { degree } \\
{[\%]^{* * *}}\end{array}$ \\
\hline LCPU-1 & $\begin{array}{c}\text { BHBP/PTMO 3:1 } \\
\text { PTMO-2000 }\end{array}$ & 32850 & 1.4 & 56.8 & -85 & 100 \\
\hline LCPU-2 & $\begin{array}{c}\text { BHBP/PTMO 1:1 } \\
\text { PTMO-2000 }\end{array}$ & 37300 & 1.5 & 76.0 & -85 & 100 \\
\hline LCPU-3 & $\begin{array}{c}\text { BHBP/PTMO 3:1 } \\
\text { PTMO-1000 }\end{array}$ & 35635 & 2.3 & 39.7 & +10 & 49 \\
\hline LCPU-4 & $\begin{array}{c}\text { BHBP/PTMO 1:1 } \\
\text { PTMO-650 }\end{array}$ & 37200 & 1.4 & 51.0 & -32 & 71 \\
\hline
\end{tabular}

* GPC, based on polystyrene standards, ${ }^{* *}$ DSC,

*** calculated as $\frac{T_{\mathrm{gHS}}-T_{\mathrm{g}}}{T_{\mathrm{gHS}}-T_{\mathrm{gSS}}}$, where $T_{\mathrm{g} S \mathrm{SS}}=-85^{\circ} \mathrm{C}\left(T_{\mathrm{g}}\right.$ of neat soft segm., exp.), $T_{\mathrm{gHS}}=100^{\circ} \mathrm{C}\left(T_{\mathrm{g}}\right.$ of neat soft segm., lit. $)$.

Polymer films used in transport studies were cast from 20\% DMF solution and dried for 4 days at $60^{\circ} \mathrm{C}$, while the ones used in PAL studies had the form of discs of $10 \mathrm{~mm}$ and the thickness of $1 \mathrm{~mm}$ and were obtained by the way of layer by layer casting.

Scheme of the synthesis of the polyurethanes is given in Fig. 1. 


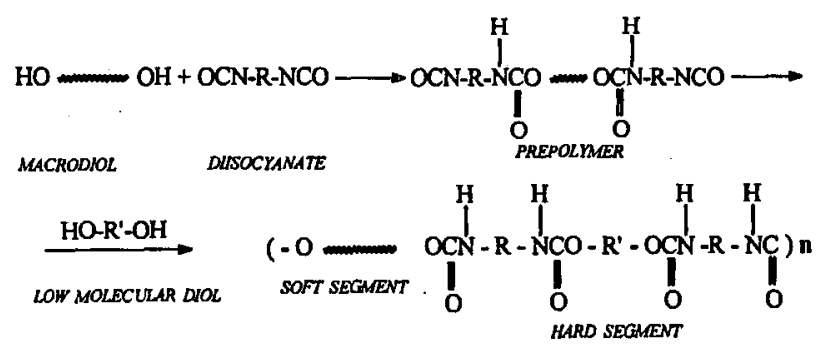

Fig. 1. Scheme of the synthesis of the polyurethanes.

\subsection{Positron annihilation lifelime (PAL) measurements}

A conventional fast-slow coincidence system with plastic, cylindrical scintillators NE111 $(20 \mathrm{~mm} \times 20 \mathrm{~mm})$ was used for measuring the lifetime spectra at room temperature. The positron source, ${ }^{22} \mathrm{Na}$ of activity $15 \mu \mathrm{Ci}$ was deposited between two identical thin Hostaphan foils $\left(0.8 \mathrm{mg} \cdot \mathrm{cm}^{-2}\right.$ each $)$ and then sand wiched between the samples under investigation. A typical decay curve contained about $2 \times 10^{6}$ counts and had the peak to background ratio of $5.5 \times 10^{4}$.

\subsection{Transport measurements}

Transport of aromatic and aliphatic hydrocarbons into LC polyurethanes was investigated using conventional weight-gain experiments.

Diffusion coefficients were evaluated from the slopes of the initial linear part of the $M_{t} / M_{\infty}$ versus $t^{1 / 2}$ curves according to the relation [5]:

$$
\frac{M_{t}}{M_{\infty}}=\left(\frac{16 D}{h^{2} \pi}\right)^{1 / 2} \cdot t^{1 / 2}
$$

where $M_{t}$ and $M_{\infty}$ are the amounts of the liquid absorbed after time $t$ and after infinite time respectively, while $h$ is the sample thickness.

\section{Results and discussion}

\subsection{Results of PAL measurements}

The PAL spectra were fitted with a sum of four exponentials convoluted with the resolution function of the lifetime spectrometer (a sum of two Gaussians) plus a constant background using the program POSITRONFIT [6]. The results of the analysis i.e. the lifetimes and the intensities are given in Table II.

The analysis of the PAL spectra with the use of the method employing numerical Laplace inversion technique [7] was performed for the samples. Further details concerning the method are given in [8]. A modified version of Provencher program CONTIN was used to obtain the volume $(V)$ distributions of free-volume cavities. A reference spectrum of $6 \mathrm{~N}$ polycrystalline $\mathrm{Ni}$ was used $\left(\tau_{\mathrm{Ni}}=116 \mathrm{ps}\right.$, $\left.I_{\mathrm{Ni}}=92 \%\right)$. The volume distributions $g(V)$ are given in Fig. 2 . 
TABLE II

Results of positron lifetime measurements.

\begin{tabular}{c|c|c|c|c|c|c|c|c}
\hline \hline \multirow{2}{*}{ Sample } & \multicolumn{4}{|c|}{ Lifetimes [ns] } & \multicolumn{4}{c}{ Intensities [\%] } \\
\cline { 2 - 9 } & $\tau_{1}$ & $\tau_{2}$ & $\tau_{3}$ & $\tau_{4}$ & $I_{1}$ & $I_{2}$ & $I_{3}$ & $I_{4}$ \\
\hline LCPU-1 & 0.21 & 0.38 & 1.52 & 2.76 & 25.3 & 46.4 & 8.9 & 19.3 \\
& $(0.02)$ & $(0.02)$ & $(0.15)$ & $(0.05)$ & $(4.9)$ & $(4.4)$ & $(1.1)$ & $(1.4)$ \\
LCPU-2 & 0.26 & 0.45 & 1.75 & 2.76 & 44.2 & 27.9 & 6.4 & 21.6 \\
& $(0.02)$ & $(0.06)$ & $(0.53)$ & $(0.11)$ & $(9.4)$ & $(8.6)$ & $(4.1)$ & $(4.8)$ \\
LCPU-3 & 0.24 & 0.44 & 1.85 & 3.02 & 39.1 & 33.3 & 19.1 & 8.5 \\
& $(0.02)$ & $(0.03)$ & $(0.12)$ & $(0.2)$ & $(5.4)$ & $(4.9)$ & $(2.4)$ & $(2.8)$ \\
LCPU-4 & 0.27 & 0.58 & 2.30 & 5.93 & 55.1 & 19.3 & 25.1 & 0.5 \\
& $(0.01)$ & $(0.04)$ & $(0.04)$ & $(1.65)$ & $(2.2)$ & $(2.0)$ & $(0.3)$ & $(0.3)$
\end{tabular}

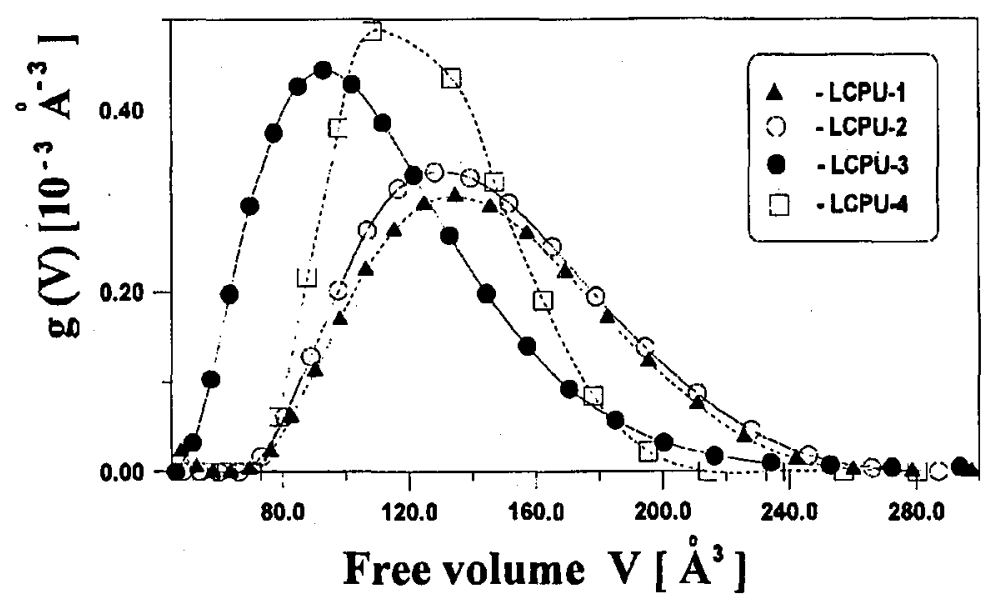

Fig. 2. Free volume distributions for studied LCPU.

TABLE III

Transport properties of LC polyurethanes.

\begin{tabular}{c|c|c|c}
\hline \hline $\begin{array}{c}\text { Diffusion coefficients } \\
D \times 10^{7}\left[\mathrm{~cm}^{2} / \mathrm{s}\right]\end{array}$ & Benzene & Cyclohexane & $n$-Iexane \\
\hline LCPU-1 & 3.0 & 0.73 & 1.12 \\
LCPU-2 & - & 1.79 & 3.15 \\
LCPU-3 & 1.36 & 0.05 & 0.11 \\
LCPU-4 & 2.02 & 0.09 & 0.25
\end{tabular}




\subsection{Transport properties of $L C$ polyurethanes at $25^{\circ} \mathrm{C}$}

Transport results for different hydrocarbons and various LC polyurethane materials are shown in Table III. The correlation between diffusion coefficients and morphology of LC polyurethane or nature of penetrant will be described in details in [9].

\subsection{Discussion}

Segmented polyurethanes can be defined as linear multi-block copolymers consisting of highly polar and rigid blocks ("hard segments") and relatively long, flexible "soft segments" (cf. Fig. 3).

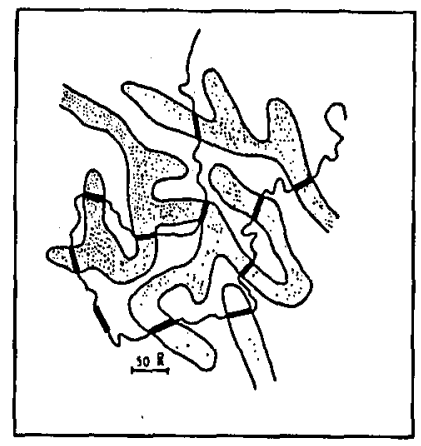

Fig. 3. Schematic representation of domain structure in segmented polyurethanes:

$\because \because \square$ hard blocks, soft blocks.

Due to thermodynamic incompatibility the hard and soft segments undergo microphase separation resulting in the formation of soft and hard domains. The latter act as physical crosslinks as well as "reinforcing" fillers.

It was shown that transport of liquids and gases in segmented polyurethanes occurs through the soft segment domains. Thus, structure and mobility of soft segments segregated into soft domains seem to be the major factors influencing diffusion of liquids through LC polyurethanes.

It has been found previously [4] that by varying the initial composition of the diols and/or molecular weight of the soft segments it is possible to influence the properties of the continuous soft segment matrix. Fairly pure soft segment matrix (Fig. 4) is assumed to be present in the case of the liquid crystalline polyurethanes (LCPU) with a soft segment of $\bar{M}_{n}=2000$, whereas LC polyurethanes with hard mesogenic blocks mixed into the soft phase were formed when $\bar{M}_{n}$ of PTMO block was lower than 2000 (Fig. 5).

The differences in structure of soft segment domains can also be seen from the results of the investigations of the LCPU by the positron annihilation. It appears from the curves shown in Fig. 2 that the average size of free volume for the LC polyurethanes which are completely phase separated (LCPU-1 and LCPU-2) is higher than for the LC polyurethanes for which phase mixing occurs (LCPU-3 and LCPU-4). 


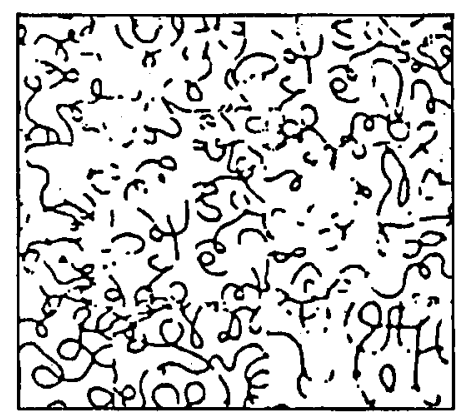

Fig. 4

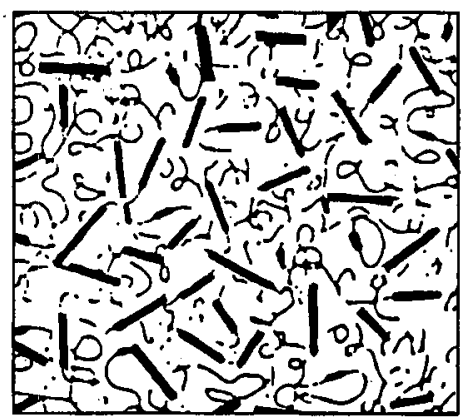

Fig.5

Fig. 4. Amorphous soft segment regions.

Fig. 5. Amorphous "solution" of hard and soft segments.

Moreover, there is a strong correlation between the values of the glass transition temperature $T_{\mathbf{g}}$ (cf. Table I), the average size of the free volume $V_{\mathrm{av}}$ (the value corresponding to the maxima in Fig. 2) and the diffusion coefficient $D$ (cf. Table III) of organic liquids i.e. the lower value of $T_{\mathrm{g}}$ the greater values of both $V_{\text {av }}$ and $D$.

The results obtained by means of the positron annihilation method may also suggest more complex structure of the analyzed soft domains than it was found previously [4].

The existence of two long-lived components in the lifetime spectra (with the lifetimes $\tau_{3}$ and $\tau_{4}$ ) can be connected with the occurrence of two structurally different "soft" regions present in soft domains. One can also assume that hard domains are not penetrated by the positronium due to their ordered structure.

The $\tau_{4}$ component corresponds to the regions of the greater free volume. Since high intensities $I_{4}$ of this component are observed for LCPU with the highest degree of the phase separation $\approx 100 \%$ (LCPU-1 and LCPU-2), one can assume that the $\tau_{4}$ component comes from the positronium annihilating in the free volume of pure elastomer domains (only blocks of PTMO). Indeed, the values of the intensities $I_{3}$ corresponding to the positronium annihilating in regions of the smaller volume $\left(\tau_{3}<\tau_{4}\right)$ are considerably lower for these polymers in comparison both with their values of $I_{4}$ and the values of $I_{3}$ for other LCPU samples (LCPU-3 and LCPU-4). Therefore, regions characterized by $\tau_{3}$ may correspond to mixed domains where the presence of the urethane blocks enlarges the intermolecular interactions that makes the chains closer to each other and results in the reduction of the free volume. Such suggestion is confirmed by the greater values of $I_{3}$ when compared to the corresponding values of $I_{4}$ obtained for samples with smaller degree of phase separation. It proves that in these samples (LCPU-3 and LCPU-4) the regions of mixed domains dominate.

\section{Acknowledgment}

This work was partially supported by the Polish-American Maria Skłodowska-Curie Joint Fund II under the grant No. PAN/NSF-94-162 and by GBW/94/5/IFD. 


\section{References}

[1] P. Penczek, K.C. Frisch, B. Szczepaniak, E. Rudnik, J. Polym. Sci. A Polym. Chem. Ed. 31, 1211 (1993).

[2] B. Szczepaniak, K.C. Frisch, P. Penczek, J. Mejsner, I. Leszczyńska, E. Rudnik, J. Polym. Sci. A Polym. Chem. Ed. 31, 3223 (1993).

[3] B. Szczepaniak, K.C. Frisch, P. Penczek, E. Rudnik, M. Cholińska, J. Polym. Sci. A Polym. Chem. Ed. 31, 3231 (1993).

[4] A. Wolin'ska-Grabczyk, submitted for publication in J. Appl. Polym. Sci.

[5] J. Crank, G.S. Park, Diffusion in Polymers, Academic Press, London 1968.

[6] P. Kirkegaard, N.J. Pedersen, M. Eldrup, PATFIT-88: A Data Processing System for Positron Annihilation Spectra on Mainframe and Personal Computers, Tech. Rep. Ris $\varnothing-M-2740$, Ris $\varnothing$ National Laboratory, Roskilde 1989.

[7] R.B. Gregory, Y. Zhu, Nucl. Instrum. Methods Phys. Res. A 290, 172 (1990).

[8] A. Baranowski, M. Dębowska, K. Jerie, G. Mirkiewicz, J. Rudzińska-Girulska, R.T. Sikorski, Acta Phys. Pol. A 83, 239 (1993).

[9] A. Woliniska-Grabczyk, I. Cabasso, B. Szczepaniak, P. Penczek, J. Membr. Sci., to be published. 